УДК 373.31

DOI: $10.23951 / 1609-624 X-2020-1-40-47$

\title{
ОСОБЕННОСТИ СОЦИАЛЬНОЙ УСПЕШНОСТИ ДЕТЕЙ МЛАДШЕГО ШКОЛЬНОГО ВОЗРАСТА ПОЛИНАЦИОНАЛЬНЫХ КЛАССОВ
}

\author{
А. Н. Пронина, И. В. Яковлева
}

Елецкий государственный университет им. И. А. Бунина, Елец

\begin{abstract}
Введение. Полиэтническая среда школы может выступать, с одной стороны, основой для проявления толерантности, межэтнического взаимодействия, с другой стороны, высокая степень этнической идентичности обучающихся может вызывать межэтнические конфликты, неприязнь к представителям иной национальности. Формирование личности младшего школьника происходит в контексте социализации, которая характеризуется стремлением к достижению успеха и социальному признанию, социальной активностью, что является показателями социальной успешности. Возникают различного рода противоречия между этнической принадлежностью и достижением социальной успешности младших школьников полинациональных классов.

Материал и методы. В исследовании изучались особенности социальной успешности младших школьников полиэтнических классов. Выборку составили младшие школьники вторых и третьих классов с полиэтническим составом $(\mathrm{n}=182)$, который представлен основной этнической группой - русских и этническим меньшинством, состоящим из обучающихся различных национальностей. Диагностика социальной успешности осуществлялась с использованием методики социометрии (Дж. Морено), опросника межличностных отношений «Мой класс» (Ю. З. Гильбух), тестирования мотиваторов социально-психологической активности личности (Н. П. Фетискин, В. В. Козлов, Г. М. Мануйлов). Для сравнения социальной успешности школьников различных этнических групп применялся параметрический t-критерий Стьюдента.

Результаты и обсуждение. Проведенное экспериментальное исследование установило уровни сформированности компонентов социальной успешности младших школьников полинациональных классов: преобладание благоприятных социометрических статусов (звезды, предпочитаемые), достижение успеха, тенденции к аффилиации, удовлетворенность школьной жизнью, низкая конфликтность и недостаточная сплоченность в основном у представителей этнического большинства. Особенности социальной успешности младших школьников полиэтнических классов заключаются в различиях конфликтности, сплоченности, тенденции к аффилиации этнического большинства и меньшинства. В совокупной выборке младших школьников полинациональных классов по позитивным показателям социально успешных обучающихся выявлено в два раза больше, чем социально неуспешных.

Заключение. Подчеркивается, что социальная успешность младших школьников полинациональных классов обусловлена не национальной принадлежностью, а другими социальными и личностными характеристиками. Изучение данных аспектов необходимо для учителей по развитию у младших школьников полинациональных классов межкультурного взаимодействия и общения, формированию толерантного отношения к представителям других этносов, пониманию способов и путей достижения социальной успешности. Материалы статьи могут быть использованы педагогами начальных классов, работающими с полинациональным составом обучающихся, психологами образовательных организаций.
\end{abstract}

Ключевые слова: младшие школьники, полинациональные классы, успешность, социальная успешность, этническое больиинство, этническое меньшинство, сочиометрический статус, мотивация достижения.

\section{Введение}

В современном мире отмечается тенденция усиления поликультурного разнообразия [1], которое обусловлено процессом миграции, переселения [2]. В условиях макросоциальных преобразований последних десятилетий в различных странах мира происходит обострение межэтнических и межкультурных конфликтов [3].

Мультикультурное образование пытается создать равные образовательные возможности для всех учащихся путем изменения общей школьной среды таким образом, чтобы она отражала различные культуры и группы в обществе и в классах [4]. Основная цель многокультурного образования заключается в предоставлении справедливых воз- можностей всем детям с различными культурными традициями [5].

Школа выступает как ключевой институт содействия социальной сплоченности в многоэтническом обществе, как ключевое учреждение для приобретения межкультурных компетенций, которые необходимы для экономической и политической интеграции граждан будущего [6].

Этническое разнообразие, по нашему мнению, должно способствовать не только улучшению межличностных отношений и повышению толерантности между представителями различных этнических групп и национальностей, но и создавать равные возможности для максимальной реализации в социуме, достижения уважения и признания себя 
представителями других национальностей, проявления социальной активности и обеспечения благоприятного статусного положения в социальной группе. В многоэтнических обществах может быть активизирована социальная сплоченность, то есть способность к диалогу с представителями других культур. Межкультурный аспект школы создает равные возможности для справедливости и равенства [6].

Актуальность изучения проблемы успеха обусловлена тем, что успех является мощной движущей силой в развитии и реализации потенциала личности. Это актуализирует субъективную позицию индивида в процессе освоения ценностей общества, которые, став лично значимыми, реализуются на практике в виде личностных достижений.

Социальная успешность отражена в небольшом количестве научных работ. Так, М. Absatova, A. Ordahanova, A. Duisenbayeva рассматривают социальную успешность как устойчивое состояние личности, основанное на позитивной «Я-концепции», что говорит о ее вовлеченности как социально полноценного субъекта в систему социальных связей и отношений, которые способствуют эффективной социализации и достижению социально значимых статусов [7].

По мнению А. Збуцки, социальная успешность - это, с одной стороны, психическое состояние человека, которое характеризуется личным удовлетворением своего положения в социальном окружении, с другой стороны, результат интеграции человека в социальную среду [8].

А. Р. Тугушева определяет социальную успешность как социально-психологическое явление, включающее оценочные суждения об эффективности личности, ее социально-психологической деятельности и поведении в социальном пространстве [9].

В структуре социальной успешности M. Absatova выделяет ядерную структуру социально успешного человека, которая включает в себя: профессиональные навыки; мотивацию, умение ставить цели; человеческие ценности (доброта, гуманизм, справедливость, сострадание к другим, терпимость, уверенность, решительность, вера в собственные силы); способность действовать в ситуациях неопределенности; построение межличностных отношений; способность к мобилизации; умение отстаивать свои интересы в социальной среде и др. [10].

В структуре социальной успешности можно выделить мотивационный, отношенческий и поведенческий показатели.

Социальная успешность в младшем школьном возрасте способствует и обеспечивает стабильность и дальнейшее позитивное социальное развитие школьника и создает предпосылки для перехода в новый возрастной этап.
В младшем школьном возрасте мы не можем говорить о достижении социального успеха, так как достичь конкретных показателей и конечных результатов социального успеха можно на более поздних возрастных этапах (юношеский, взрослость), но мы можем говорить о социальной успешности как процессе и показателе динамики достижения социального успеха.

Фактором, влияющим на достижение социального успеха, можно также считать и этническую идентичность, которая может как положительно, так и отрицательно влиять на многие аспекты социальной успешности.

Социальную успешность младших школьников в полиэтнических классах, по нашему мнению, следует понимать как процесс и показатель позитивной социализации школьника в полиэтнической среде, которая выражается в балансе между внутренним состоянием удовлетворенности собственной этнической идентичностью и внешней социальной активностью, направленной на установление позитивных межличностных отношений с одноклассниками других этносов, достижением благоприятного социального статуса в классе и позитивным социально-психологическим состоянием удовлетворения.

Этнический состав школ также может играть определенную роль в достижении социальной успешности посредством установления потенциальных контактов представителей различных этнических групп [11], где каждый школьник стремится завоевать уважение, популярность, получить социальное признание, иметь успех среди одноклассников.

Доминирование и подчинение в отношениях между представителями этнического большинства и меньшинства характеризуют разницу власти и влияния между группами. Частое взаимодействие между членами этнических групп может способствовать культурному взаимодействию и укреплению отношений, создает большие возможности в понимании друг друга [12].

В некоторых исследованиях в самом определении этнической идентичности обозначено препятствие к достижению социальной успешности. Так, в работе Т. Г. Стефаненко этническая идентичность понимается как переживания отношений Я и этнической среды - своего тождества с одной этнической общностью и отделения от других [13].

В теории социальной идентичности выдвигается положение о том, что этническая идентичность позволяет формировать положительные отношения с представителями аналогичной идентичности и препятствует построению отношений между различными этническими группами. Эти теории уместны в школе [12]. 
Ученые предположили, что этническая идентичность более характерна для этнического меньшинства, чем большинства [14]. В значительной степени данное предположение основано на идее о том, что сила и значимость этнической принадлежности определяются опытом, связанным с групповым статусом в обществе. Для членов этнических меньшинств, которые имеют меньшую власть и статус, подвержены дискриминации, это включает борьбу за равенство, признание в обществе, в котором доминирует большинство [15].

Достижение социальной успешности осуществляется непосредственно в социальных группах (классах, коллективах). Многоуровневый анализ показал, что мультикультурные убеждения одноклассников положительно связаны с этническим аутгрупповым отношением учащихся, особенно у детей, которые чувствуют себя более принятыми сверстниками, и отрицательно - с их отношением к ингруппе. Эти связи были опосредованы личными многокультурными убеждениями учащихся и не зависели от доли представителей одной этнической группы в классе [16].

Зарубежными исследователями изучалась проблема отношения обучающихся этнического большинства и меньшинства к аутгруппе в полиэтнических классах. Наличие понравившихся одноклассников из группы меньшинств приводит к более позитивным отношениям в группе. Наличие нелюбимых одноклассников из группы меньшинств приводит к более негативным отношениям в группе [17].

Для достижения индивидуальной успешности личности возможно использование таких методов, как конкуренция, соревнование. Вместе с тем отдельные исследования указывают на то, что достижение успехов возможно через сотрудничество, которое по сравнению с конкурентными и индивидуалистическими усилиями имеет тенденцию приводить к более высоким достижениям и производительности, более позитивным межличностным отношениям [18].

Цель эксперимента: выявление особенностей социальной успешности младших школьников полиэтнических классов.

Задачи исследования:

- установить сформированность компонентов социальной успешности младших школьников полиэтнических классов;

- сравнить сформированность компонентов социальной успешности младших школьников этнического большинства и меньшинства;

- определить соотношение социально успешных и неуспешных младших школьников различных национальностей в полиэтническом классе.

Мы предположили, что в полиэтнических класcax в группу социально успешных младших школьников войдут школьники этнического большинства, а группу социально неуспешных составят школьники этнического меньшинства.

В эмпирическом исследовании принимали участие младшие школьники 2-х и 3-х классов с полиэтническим составом $(\mathrm{n}=182)$ Липецкой области. В данных классах этническое большинство составили русские $(\mathrm{n}=103)$, в этническое меньшинство вошли цыгане, армяне, узбеки, таджики, украинцы $(\mathrm{n}=79)$. Возраст участников эксперимента составил 8-9 лет. Среднее значение возраста испытуемых - 8,6. Стандартное отклонение $\pm 0,4$.

Исследование проводилось в три этапа.

На первом этапе проводилась диагностика социальной успешности школьников с помощью трех методик: методика социометрии (Дж. Морено) для определения социального положения школьников в группе сверстников; опросник «Мой класс» (Ю. 3. Гильбух) - для определения степени удовлетворенности школьной жизнью, конфликтности в классе, его сплоченности; тестирование мотиваторов социально-психологической активности личности (Н. П. Фетискин, В. В. Козлов, Г. М. Мануйлов), направленное на выявление тенденций к достижению успеха, стремления к власти, аффилиации.

Методика социометрии (Дж. Морено) проводилась индивидуально. Каждому школьнику из класса предлагали перечислить и записать по степени значимости и в порядке предпочтения тех одноклассников (ограничивались тремя выборами одноклассников), с которыми они хотели бы вместе участвовать в учебной деятельности, совместной работе, сидеть за партой, дружить. По результатам совершенного выбора составлялась социометрическая матрица и подсчитывалось количество сделанных выборов в пользу отдельных членов группы, которых распределили на соответствующие статусные группы: лидеры, или «звезды» (5 и 6 выборов); предпочитаемые (3-4 выбора); пренебрегаемые (1-2 выбора); изолированные (0 выборов); микрогруппы (группы детей, избравших друг друга).

Методика опроса «Мой класс» (Ю. 3. Гильбух) проводилась индивидуально. Опросник состоял из 15 утверждений, разделенных на 3 блока, по пять в каждом: 1-й блок - степень удовлетворенности школьной жизнью; 2-й блок - степень конфликтности в классе; 3-й блок - степень сплоченности. Школьникам предлагалось выразить согласие с конкретным утверждением («Да») либо несогласие («Нет»). За каждое согласие/несогласие по соответствующему утверждению присваивался конкретный балл $(3,2,1)$. Затем подсчитывалась сумма баллов по каждому блоку. Максимальная сумма баллов свидетельствовала о высокой степени выраженности удовлетворенности школьной жизнью, конфликтности и сплоченности в классе. 
Тестирование мотиваторов социально-психологической активности личности (Н. П. Фетискин, В. В. Козлов, Г. М. Мануйлов) представляло собой индивидуальное заполнение школьниками бланка с 15 утверждениями, которые распределены на три блока, выявляющие такие мотиваторы социальной успешности, как достижение успеха в целом, стремление к власти, тенденция к аффилиации (групповому признанию и уважению). На каждое утверждение школьнику предлагалось выбрать балл от 5 до 1 , соответствующий степени согласия. Суммирование баллов по каждому блоку определяло доминирующий социальный мотив, а также уровень его сформированности.

На втором этапе - сравнение социальной успешности младших школьников этнического большинства и этнического меньшинства с применением параметрического t-критерия Стьюдента с помощью программы SPSS Statistics.

На третьем этапе осуществлялось распределение младших школьников на две группы социальной успешности (успешные, неуспешные). Нам необходимо было определить, каково соотношение социально успешных и социально неуспешных школьников в полиэтнических классах и каков этнический состав данных групп.

\section{Результаты и обсуждение}

Диагностика, направленная на выявление социометрического статуса как одного из показателя социальной успешности с применением методики социометрии (Дж. Морено), выявила следующие статусные категории в группах (классах) младших школьников: «звезды» (лидеры) - 34 \%; предпочитаемые - $42 \%$; пренебрегаемые - $18 \%$; изолированные $-6 \%$ (рис. 1).

Выявление межличностных отношений в классе как показателя социальной успешности с использованием опросника «Мой класс» (Ю. З. Гильбух) показало высокую степень удовлетворенности школьной жизнью у 68 \% школьников, среднюю - у 21 \%, низкую - у $11 \%$. Высокая степень конфликтности в классе определяется у $19 \%$ школьников, средняя - у $27 \%$, низкая - у $54 \%$ опрашиваемых. Высокая степень сплоченности установлена у $36 \%$ школьников, средняя - у $44 \%$, низкая - у $20 \%$. Результаты опросника «Мой класс» (Ю. 3. Гильбух) представлены в табл. 1.

В подгруппы различной степени выраженности показателя удовлетворенности школьной жизнью вошли школьники различных этнических групп. Подгруппу с высокой степенью конфликтности в классе составили школьники этнического большинства (русские) (осознают степень своего количественного превосходства перед меньшинством), а подгруппу низкой конфликтности в классе составили школьники национальных меньшинств.
Высокую сплоченность продемонстрировали обучающиеся этнических меньшинств, а низкую сплоченность - представители русской национальности.

Тестирование по выявлению у младших школьников из полинациональных классов мотиваторов социально-психологической активности личности (Н. П. Фетискин, В. В. Козлов, Г. М. Мануйлов), которые демонстрируют стремление к социальной успешности и выражаются в проявлении потребностей в достижении успеха, стремлении к власти, тенденцией к аффилиации, позволило получить следующие данные (табл. 2).

Сравнение социальной успешности младших школьников этнического большинства и этнического меньшинства с применением параметрического t-критерия Стьюдента показало некоторые различия данными группами (табл. 3).

Нами установлено, что между сформированностью компонентов социальной успешности обучающихся этнического большинства и меньшинства имеются различия конфликтности, сплоченности, тенденции к аффилиации.

Результаты реализации третьего этапа эксперимента позволили распределить младших школьников из полинациональных классов на две группы: социально успешные и социально неуспешные. К социально успешным отнесены школьники с благоприятными социометрическими статусами («звезды», предпочитаемые), с высокой и средней степенью удовлетворенности школьной жизнью, низкой степенью конфликтности, высокой и средней степенью сплоченности, высоким и средним уровнем достижения успеха и тенденции к аффилиации, высоким и средним уровнем стремления к власти. Таких обучающихся выявлено $66 \%$ $(\mathrm{n}=120)$.

В группу социально неуспешных вошли школьники с неблагоприятными социометрическими статусами (пренебрегаемые, изолированные), с низкой степенью удовлетворенности школьной жизнью, высокой и средней степенью конфликтности, низкой степенью сплоченности, низким уровнем достижения успеха и тенденции к аффилиации, низким уровнем стремления к власти. В данную группу вошли $34 \%(n=62)$ младших школьников из полиэтнических классов (рис. 2).

Анализ этнического состава школьников, входящих в каждую группу, показал, что в группы социально успешных и социально неуспешных вошли как представители этнического большинства, так и этнического меньшинства и социально неуспешных.

\section{Заключение}

В исследовании изучались особенности социальной успешности младших школьников полиэтнических классов. 


\section{Социометрические статусы}

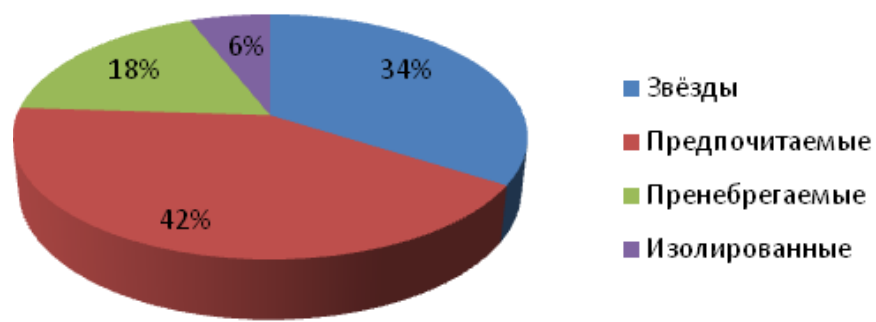

Рис. 1. Процентное распределение социометрических статусов младших школьников в полиэтнических классах

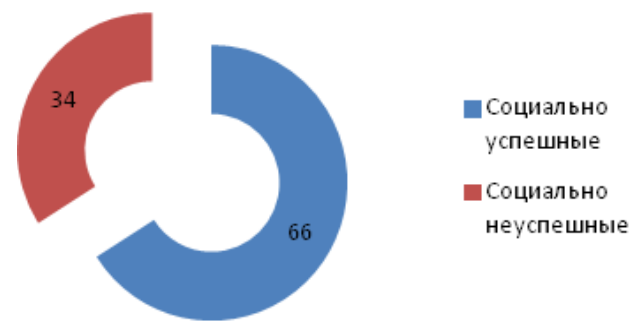

Рис. 2. Распределение младших школьников из полиэтнических классов на социально успешных и социально неуспешных

Таблица 1

Процентное соотношение, среднее значение и стандартное отклонение степени выраженности удовлетворенности школьной жизнью, конфликтности и сплоченности младших школьников полиэтнических классов

\begin{tabular}{|l|c|c|c|c|}
\hline \multirow{2}{*}{ Показатели } & \multicolumn{3}{|c|}{ Степени выраженности, \% } & \multirow{2}{*}{$\begin{array}{c}\text { Среднее значение / } \\
\text { стандартное отклонение }\end{array}$} \\
\cline { 2 - 4 } & высокая & средняя & низкая & $8,3 / 3,2$ \\
\hline $\begin{array}{l}\text { Удовлетворенность школьной } \\
\text { жизнью }\end{array}$ & 68 & 21 & 11 & $4,6 / 1,4$ \\
\hline Конфликтность в классе & 19 & 27 & 54 & $7,4 / 2,5$ \\
\hline Сплоченность & 36 & 44 & 20 & \\
\hline
\end{tabular}

Таблица 2

Распределение уровней сформированности, среднего значения и стандартного отклонения мотивационных потребностей социально-психологической активности у младиих школьников полиэтнических классов

\begin{tabular}{|l|c|c|c|c|}
\hline \multirow{2}{*}{ Потребности } & \multicolumn{2}{|c|}{ Уровень сформированности, \% } & \multirow{2}{*}{$\begin{array}{c}\text { Среднее значение / } \\
\text { стандартное отклонение }\end{array}$} \\
\cline { 2 - 4 } & высокий & средний & низкий & $13,3 / 4,1$ \\
\hline Достижение успеха в целом & 55 & 28 & 17 & $10,2 / 3,5$ \\
\hline Стремление к власти & 23 & 46 & 31 & $12,4 / 2,6$ \\
\hline $\begin{array}{l}\text { Тенденция к аффилиации (группо- } \\
\text { вому признанию и уважению) }\end{array}$ & 56 & 29 & 15 & \\
\hline
\end{tabular}

Таблица 3

Сравнение компонентов социальной успешности в выборках этнического большинства и меньшинства младших школьников полиэтнических классов по t-критерию Стьюдента

\begin{tabular}{|l|c|c|c|c|c|c|c|}
\hline $\begin{array}{c}\text { Компоненты социальной } \\
\text { успешности }\end{array}$ & $\begin{array}{c}\text { Социоме- } \\
\text { трический } \\
\text { статус }\end{array}$ & $\begin{array}{c}\text { Удовлетво- } \\
\text { ренность } \\
\text { школьной } \\
\text { жизнью }\end{array}$ & $\begin{array}{c}\text { Конфлик- } \\
\text { тность в } \\
\text { классе }\end{array}$ & $\begin{array}{c}\text { Сплочен- } \\
\text { ность }\end{array}$ & $\begin{array}{c}\text { Достижение } \\
\text { успеха в } \\
\text { целом }\end{array}$ & $\begin{array}{c}\text { Стремление } \\
\text { к власти }\end{array}$ & $\begin{array}{c}\text { аенденция килиции } \\
\text { (групповому } \\
\text { признанию } \\
\text { и уважению) }\end{array}$ \\
\hline $\begin{array}{l}\text { Значимость различий } \\
\text {-критерия Стьюдента }\end{array}$ & 0,001 & 0,55 & $2,43 *$ & $2,01 *$ & 0,51 & 0,003 & $2,44 *$ \\
\hline
\end{tabular}

$* p<0,05$. 
Данные, полученные в ходе выявления социометрического статуса младших школьников полинациональных классов, показали, что учащиеся других национальностей могут занимать как самые высокие социометрические позиции, так и самые низкие. Нами обнаружена высокая степень удовлетворенности школьной жизнью младшими школьниками, которые учатся в полиэтническом классе. Вместе с тем установлена высокая степень конфликтности школьников разных национальностей в полиэтнических классах. На фоне высокой конфликтности школьников различных национальностей естественным образом выглядит средняя степень сплоченности, что не является позитивным показателем социальной успешности.

В эксперименте выявлен высокий уровень достижения успеха в целом младшими школьниками полиэтнических классов. Эти данные подтверждают возможность достижения успехов в школе учащимися других национальностей.

Установлен высокий уровень аффилиации (групповое признание и уважение) младших школьников, т. е. в данном возрасте для достижения социальной успешности необходимо быть не просто полноправным членом группы, класса, но и получить, вызвать, заслужить соответствующее к себе положительное, удовлетворительное отношение со стороны одноклассников.

Мы считаем, что высокий социометрический статус, удовлетворенность школьной жизнью, до- стижение успеха обучающихся разной национальности обеспечиваются не их этнической принадлежностью и этническими характеристиками, а другими особенностями, необходимыми и ценными для дружбы, взаимодействия, совместной учебной и внеучебной деятельности (активность, эмпатийность, толерантность, академические достижения и т. д.).

Различия конфликтности, сплоченности обусловлены этнической идентичностью и проблемами социализации этнических меньшинств в другой национальной среде, а различия в тенденции к аффилиации объясняются стремлением этнического меньшинства к принятию в более широкую социальную группу.

Для получения более точных данных о влиянии национальности на социальную успешность необходимо проведение дополнительного исследования.

Результаты данного исследования могут расширить и обогатить методы, программы, направленные на социальную адаптацию и конструктивную позитивную социальную успешность младших школьников в полиэтнической среде, посредством сохранения и осознания этнической идентичности, коррекции методов и приемов ее сохранения, осознания и направить отдельные ее составляющие на формирование терпимости, миролюбия, толерантности, педагогических и психологических механизмов преодоления негативной этнической идентичности.

\section{Список литературы}

1. Phalet K., Baysu G., Acker K. V. Ethnicity and Migration in Europe // International Encyclopedia of the Social \& Behavioral Sciences (Second Edition). 2015. P. 142-147. DOI: https://doi.org/10.1016/B978-0-08-097086-8.24040-3

2. Coleman D. Migrants and Migration in Europe // International Encyclopedia of the Social \& Behavioral Sciences (Second Edition). 2015. P. 376388. DOI: https://doi.org/10.1016/B978-0-08-097086-8.31122-9

3. Light M. T. Re-examining the relationship between Latino immigration and racial/ethnic violence //Social Science Research. 2017. Vol. 65. July. P. 222-239. DOI: https://doi.org/10.1016/j.ssresearch. 2017.03.005

4. Cirik I. Investigation of the Relations Between Objectives of Turkish Primary School Curriculums and Multiculturalism // Procedia - Social and Behavioral Sciences. 2014. Vol. 116. P. 74-76. DOI: 10.1016/j.sbspro.2014.01.170

5. Omar N., Che Noh M. A., Hamzah M. I., Majid L. A. Multicultural education practice in Malaysia // Procedia - Social and Behavioral Sciences. 2015. Vol. 174. P. 1941-1948. DOI: 10.1016/j.sbspro.2015.01.859

6. Contini R. M. Interculturality and Social Bonds Formation: a Case Study on Immigrant and Native Preadolescents in Italy // Procedia - Social and Behavioral Sciences. 2014. Vol. 149. P. 233-241. DOI: 10.1016/j.sbspro.2014.08.223

7. Absatova M., Ordahanova A., Duisenbayeva A. Social Success of Future Primary School Teachers in the Process of Professional Training // Mediterranean Journal of Social Sciences. 2015. Vol. 6. P. 476-481. DOI: http://dx.doi.org/10.5901/mjss.2015.v6n6s4p476.

8. Збуцки А. Формирование социальной успешности школьников средствами экономического образования: дис. ... канд. пед. наук. Ярославль, 2005. 144 с.

9. Тугушева А. Р. Особенности образа социально успешного человека в представлениях молодежи // Проблемы социальной психологии личности. Саратов: Изд-во Саратовского ун-та, 2006. Вып. 3. С. 87-93.

10. Absatova M., Ussenova A., Kariyev A., Tashseva A., Karakulova M. Structural and Substantive Characteristics of The Concept «Social Success» // Procedia - Social and Behavioral Sciences. 2015. Vol. 197. P. 2425-2429. DOI: 10.1016/j.sbspro.2015.07.305

11. Migliorini L., Rania N., Cardinali P. Intercultural learning context and acculturation strategies // Procedia - Social and Behavioral Sciences. 2015. Vol. 171. P. 374-381. DOI: 10.1016/j.sbspro.2015.01.135

12. Ahmad Y., Yusof N. M. Ethnic Boundary among Students in Malaysian Primary Schools and Social Interaction: A Conceptual Framework // Procedia Social and Behavioral Sciences. 2010. Vol. 7. P. 82-91. DOI: 10.1016/j.sbspro.2010.10.013 
13. Стефаненко Т. Г. Этническая идентичность: от этнологии к социальной психологии // Вестник Московского ун-та. Сер. 14: Психология. 2009. № 2. C. 3-17.

14. Umaña-Taylor A. J., O'Donnell M., Knight P. G., Roosa M. W., Berkel C., Nair R. Mexican-origin early adolescents' ethnic socialization, ethnic identity, and psychosocial functioning // The Counseling Psychologist. 2014. Vol. 42. P. 170-200. DOI: 10.1177/0011000013477903

15. Zbarauskaitè A., Grigutytè N., Gailienè D. Minority Ethnic Identity and Discrimination Experience in a Context of Social Transformations // Procedia - Social and Behavioral Sciences. 2015. Vol. 165. P. 121-130. DOI:10.1016/j.sbspro.2014.12.613

16. Thijs J., Verkuyten M. Multiculturalism in the classroom: Ethnic attitudes and classmates' beliefs // International Journal of Intercultural Relations. 2013. Vol. 37, is. 2. P. 176-187. DOI: https://doi.org/10.1016/j.ijintrel.2012.04.012

17. Stark T. H., Mäs M., Flache A. Liking and disliking minority-group classmates: Explaining the mixed findings for the influence of ethnic classroom composition on interethnic attitudes // Social Science Research. 2015. Vol. 50. P. 164-176. DOI: https://doi.org/10.1016/j.ssresearch.2014.11.008

18. Johnson D. W., Johnson R. T. Cooperation and Competition//International Encyclopedia of the Social \& Behavioral Sciences (Second Edition). 2015. P. 856-861. DOI: https://doi.org/10.1016/B978-0-08-097086-8.24051-8

Пронина Анжелика Николаевна, доктор педагогических наук, доцент, профессор, Елецкий государственный университет им. И. А. Бунина (ул. Коммунаров, 28, Елец, Россия, 399770). E-mail: antipi-elena@yandex.ru

Яковлева Ирина Васильевна, старший преподаватель, Елецкий государственный университет им. И. А. Бунина (ул. Коммунаров, 28, Елец, Россия, 399770). E-mail: yakovlevairinavas070882@mail.ru

Материал поступил в редакиию 28.08.2019.

DOI: 10.23951/1609-624X-2020-1-40-47

FEATURES OF SOCIAL SUCCESS OF CHILDREN OF PRIMARY SCHOOL AGE OF MULTINATIONAL CLASSES

\section{A. N. Pronina, I. V. Yakovleva}

Bunin Yelets State University, Yelets, Russian Federation

Introduction. The multiethnic environment of the school can act, on the one hand, as the basis for the manifestation of tolerance, interethnic interaction, and on the other hand, a high degree of ethnic identity of students can cause interethnic conflicts and hostility to representatives of a different nationality. The formation of the personality of a younger student takes place in the context of socialization, which is characterized by a desire for success and social recognition, social activity, which are indicators of social success. Various kinds of contradictions arise between ethnicity and the achievement of the social success of elementary schoolchildren in multinational classes.

The aim of the study was to study the features of social success of younger students of polyethnic classes. The objectives of the study were to determine the formation of components of social success of primary school students, to establish differences between the components of social success of the ethnic majority and minority, to identify the ratio of socially successful and socially unsuccessful students of polyethnic classes. The sample was made by primary school children of 2 and 3 classes with a multi-ethnic composition $(n=182)$, which is represented by the main ethnic group - Russians and an ethnic minority consisting of students of different nationalities. Diagnosis of social success was carried out using the methodology of sociometry (J. Moreno), questionnaire of interpersonal relations "My class" (Yu. Z. Gil'bukh) testing motivators socio-psychological activity of a person (N. P. Fetiskin, V. V. Kozlov, G. M. Manuylov). The parametric student t-test was used to compare the social success of students of different ethnic groups.

Results and discussion. Experimental research has established the levels of formation of the components of social success of elementary schoolchildren of multinational classes: the prevalence of favorable sociometric status (stars, the preferred), achievement of success, tendency for affiliation, the school life satisfaction, low conflict and lack of solidarity, mainly among representatives of the ethnic majority. The features of the social success of primary school students of multiethnic classes are the differences in conflict, solidarity, and the tendency to the affiliation of the ethnic majority and minorities. In the total sample of elementary schoolchildren of multinational classes, by the positive indicators of socially successful students, twice as many were identified as socially unsuccessful.

Conclusion. It is emphasized that the social success of primary school students of multi-national classes is not due to national affiliation, but other social and personal characteristics. The study enriches and complements the pedagogy of primary school, the theory and methodology of education of younger students with new data on the socialization of the child's personality in the system of interethnic interaction, the features of social success of students at the stage of primary education. The study of these aspects is necessary for primary school teachers working with a multi-ethnic composition of students to develop intercultural interaction and communication among younger students, the formation of a tolerant attitude to representatives of other ethnic groups, understanding ways and means of achieving social success.

Keywords: primary school children; multi-national classes; success; social success; ethnic majority, ethnic minority. 


\section{References}

1. Phalet K., Baysu G., Acker, K. V. Ethnicity and Migration in Europe. In: International Encyclopedia of the Social \& Behavioral Sciences (Second Edition), 2015, pp. 142-147. DOI: https://doi.org/10.1016/B978-0-08-097086-8.24040-3.

2. Coleman D. Migrants and Migration in Europe. In: International Encyclopedia of the Social \& Behavioral Sciences (Second Edition), 2015, pp. 376-388. DOI: https://doi.org/10.1016/B978-0-08-097086-8.31122-9.

3. Light M. T. Re-examining the relationship between Latino immigration and racial/ethnic violence. Social Science Research, 2017, vol. 65 July, pp. 222-239. DOI: https://doi.org/10.1016/j.ssresearch. 2017.03.005

4. Cirik I. Investigation of the Relations Between Objectives of Turkish Primary School Curriculums and Multiculturalism. Procedia - Social and Behavioral Sciences, 2014, vol. 116, pp. 74-76. DOI: 10.1016/j.sbspro.2014.01.170

5. Omar N., Che Noh M. A., Hamzah M. I., Majid L. A. Multicultural education practice in Malaysia. Procedia - Social and Behavioral Sciences, 2015, vol. 174, pp. 1941-1948. DOI: 10.1016/j.sbspro.2015.01.859

6. Contini R. M. Interculturality and Social Bonds Formation: a Case Study on Immigrant and Native Preadolescents in Italy. Procedia - Social and Behavioral Sciences, 2014, vol. 149, pp. 233-241. DOI: 10.1016/j.sbspro.2014.08.223

7. Absatova M., Ordahanova A., Duisenbayeva A. Social Success of Future Primary School Teachers in the Process of Professional Training. Mediterranean Journal of Social Sciences, 2015, vol. 6, pp. 476-481. DOl: http://dx.doi.org/10.5901/mjss.2015.v6n6s4p476.

8. Zbutski A. Formirovaniye sotsial'noy uspeshnosti shkol'nikov sredstvami ekonomicheskogo obrazovaniya. Dis. kand. ped. nauk [Formation of school students' social success by means of economic education. Diss. kand. of ped. sci.].Yaroslavl, 2005. 144 p. (in Russian).

9. Tugusheva A. R. Osobennosti obraza sotsial'no uspeshnogo cheloveka v predstavleniyakh molodezhi [Features of the image of a socially successful person in the views of young people]. Problemy sotsial'noy psikhologii lichnosti [Problems of social psychology of personality]. Saratov, Saratov University Publ., 2006, is. 3, pp. 87-93 (in Russian).

10. Absatova M., Ussenova A., Kariyev A., Tashseva A., Karakulova M. Structural and Substantive Characteristics of The Concept «Social Success». Procedia - Social and Behavioral Sciences, 2015, vol. 197, pp. 2425-2429. DOI: 10.1016/j.sbspro.2015.07.305

11. Migliorini L., Rania N., Cardinali P. Intercultural learning context and acculturation strategies. Procedia - Social and Behavioral Sciences, 2015,vol. 171, pp. 374-381. DOI: 10.1016/j.sbspro.2015.01.135

12. Ahmad Y., Yusof N. M. Ethnic Boundary among Students in Malaysian Primary Schools and Social Interaction: A Conceptual Framework. Procedia Social and Behavioral Sciences, 2010, vol. 7, pp. 82-91. DOI:10.1016/j.sbspro.2010.10.013

13. Stefanenko T. G. Etnicheskaya identichnost': ot etnologii k sotsial'noy psikhologii [Ethnic identity: from ethnology to social psychology]. Vestnik Moskovskogo universiteta. Seriya 14. Psikhologiya - The Moscow University Herald. Series 14. Psychology, 2009, no. 2, pp. 3-17 (in Russian).

14. Umaña-Taylor A.J., O'Donnell M., Knight P. G., Roosa M. W., Berkel C., Nair R. Mexican-origin early adolescents' ethnic socialization, ethnic identity, and psychosocial functioning. The Counseling Psychologist, 2014, vol. 42, pp. 170-200. DOI: 10.1177/0011000013477903

15. Zbarauskaitè A., Grigutytė N., Gailienè D. Minority Ethnic Identity and Discrimination Experience in a Context of Social Transformations. Procedia - Social and Behavioral Sciences, 2015, vol. 165, pp. 121-130. DOI:10.1016/j.sbspro.2014.12.613

16. Thijs J., Verkuyten M. Multiculturalism in the classroom: Ethnic attitudes and classmates' beliefs. International Journal of Intercultural Relations, 2013, vol. 37, is. 2, pp. 176-187. DOl: https://doi.org/10.1016/j.jijntrel.2012.04.012

17. Stark T. H., Mäs M., Flache A. Liking and disliking minority-group classmates: Explaining the mixed findings for the influence of ethnic classroom composition on interethnic attitudes. Social Science Research, 2015, vol. 50, pp. 164-176. DOI: https://doi.org/10.1016/j.ssresearch.2014.11.008

15. Johnson D. W., Johnson R. T. Cooperation and Competition. In: International Encyclopedia of the Social \& Behavioral Sciences (Second Edition). 2015. P. 856-861. DOI: https://doi.org/10.1016/B978-0-08-097086-8.24051-8

Pronina A. N., Bunin Yelets State University (ul. Kommunarov, 28, Yelets, Russian Federation, 399770). E-mail: antipi-elena@yandex.ru

Yakovleva I. V., Bunin Yelets State University (ul. Kommunarov, 28, Yelets, Russian Federation, 399770). E-mail: yakovlevairinavas070882@mail.ru 